\title{
Medical Ethics Knowledge and Awareness Assessment Among Dentists in Nineveh Governorate (Cross Sectional Study)
}

\author{
Rawaa Younus Al-Rawee ${ }^{1, ~}$, Waleed Mohamed Basheer Alsabea ${ }^{2}$, Obaid Fakhri Hameed ${ }^{3}$ \\ ${ }^{1}$ Oral and Maxillofacial Surgery Department, Al-Salam Teaching Hospital, Ministry of Health, Mosul, Iraq \\ ${ }^{2}$ Technical Affairs Department, Nineveh Health Directorate, Ministry of Health, Mosul, Iraq \\ ${ }^{3}$ Training and Human Development Center, Nineveh Health Directorate, Ministry of Health, Mosul, Iraq
}

Email address:

dr.rawarawi@yahoo.com (R. Y. Al-Rawee), alsabeewal@gmail.com (W. M. B. Alsabea), obaidhameed894@yahoo.com (O. F. Hameed)

${ }^{*}$ Corresponding author

\section{To cite this article:}

Rawaa Younus Al-Rawee, Waleed Mohamed Basheer Alsabea, Obaid Fakhri Hameed. Medical Ethics Knowledge and Awareness Assessment Among Dentists in Nineveh Governorate (Cross Sectional Study). International Journal of Clinical Oral and Maxillofacial Surgery. Vol. 6, No. 2, 2020, pp. 26-33. doi: 10.11648/j.ijcoms.20200602.12

Received: May 16, 2020; Accepted: May 28, 2020; Published: June 20, 2020

\begin{abstract}
Medical ethics principles are universally accepted. However, each country can make some modifications and develop specific clarifications reliable with countries' existing culture. As with any profession, dentists have a responsibility to their patients and communities in which they practice, more over it is essential that dental professionals understand and practice honestly the code of ethics which is approved by the ministry of health in Iraq. Researcher aim is to highlighting the importance of ethics in general and dentistry as specific; understand the different echelons in knowledge between professional's dentists and to identify dental intern level of understanding the ethics responsibilities were given in the questionnaire. A cross-sectional questionnaire study was accomplished among three groups of dentist in Nineveh. The sample size of 240 participants was calculated from the total number of dentists (979) in Nineveh allocated between intern resident, general practitioners and dental specialist. For data collection we use a revised specialized questionnaires published by Satish Deo and his colleagues in 2018. A self-administered, 40 - itemed questioner encompassing four sections: general information, knowledge, attitude, and practice of ethics in dental healthcare were employed. Data are statistically analyzed shows that most dentists' age is ranged between two levels (less than $28 \mathrm{y}$ and from 36 to 43y) with mean age (36.66 years). In spite of that females are forming the high percentage (63.8) in practitioners group but no sex predilection in the total result. Specialist show high significant scores in the statistical analysis when compared with practitioners and interns. The last group shows the least level in knowledge. Concluding from this study that reputation to be part of medical healthcare persons make dentist forced to follow the ethical roles in the country where he live and should be an ideal example for others in the society as we are the mirrors of each other's.
\end{abstract}

Keywords: Medical Ethics, Dental Intern Doctors, Cross Sectional Study, Dental Ethics Knowledge, Dental Ethics Awareness

\section{Introduction}

Ethics can be defined as vocal code of demeanor that incorporates both professional character and judgment.

Human action on morality regarding what is correct or not is the basic principles of ethics; as ethics are moral principles and have been described as the science of morals and rules of conduct in human life $[1,2]$.
The word ethics [Greek ethos] are typically used interchangeably with the word moral [Latin word mores], which means customs or habits [3].

Ethics is the science of morality. "Hippocratic Oath," "Nuremberg Code," and "Declaration of Helsinki" were significant steps towards the management of ethics in health [4].

Medical ethics principles are universally accepted. 
However, each country can make some modifications and develop specific clarifications reliable with countries' existing culture, religion, beliefs, social norms, laws of the country, and medical practice standards in the health-care system [5].

Dental ethics is defined as "a philosophy of human conduct, a way of stating and evaluating principles by which problems of behavior can be solved" [6]. Ethics in dentistry has been ignored for decades [4].

Today's societies have become multifaceted and intricate. Dentist as a part of this society can face different ethical obstacles that deals with human rights and liberties.

The FDI International Principles of Ethics for the Dental Profession [7], states that: "The professional dentist:

Will practice according to the art and science of dentistry and to the principles of humanity.

Will safeguard the oral health of patients irrespective of their individual status".

Dr. Abdul-Salam S. Sultan [8] publishes a book about the principles of medical ethics in Iraqi health institutions in December / 2017. The author discusses widely the medical ethics in Arabic language to be more understandable by the readers. He highlight the fundamental principles and simplify a set of professional responsibilities should recognized by all health care workers in their different professions.

As with any profession, dentists have a responsibility to their patients and communities in which they practice, more over it is essential that dental professionals understand and practice honestly the code of ethics which is approved by the ministry of health in Iraq.

In this current study we aims to highlighting the importance of medical ethics in dentistry also visualize and understand the different echelons in knowledge between professional's dentists. Define ethics theories and apply them to ethical issues in everyday practice. Finally to identify dental intern level of understanding the ethics responsibilities were given in the questionnaire.

\section{Material and Methods}

Ethical Approval: This study followed the Declaration of Helsinki on medical protocol and ethics and the study approved by the institutional research committee in Nineveh Health Directorate number 194 by license number $20 / 33$ in $11 / 3$ / 2020.

\subsection{Study Setting}

A cross-sectional questionnaire study was accomplished for two months duration from July to September 2019 among three groups of dentists in Nineveh. We chose the Dental Health Centers (D. H. C.) and these are (Al-Noor D. H. C., Left D. H. C., Right D. H. C.).

\subsection{Study Population}

In each group we try to have 80 mutual. The sample size of 240 was calculated from the total number of dentists (979) in
Nineveh allocated between dental intern (resident) doctors (ID), dental practitioner doctors (DP) and dental specialist doctors (DS).

Groups are:

First group (DI.) are dental intern doctors registered in the Dental Health Centers (Al-Noor D. H. C., Left D. H. C., Right D. H. C.).

Second group (DP.) are the dental practitioners responsible for the clinical training of the intern.

Third group (DS.) are the dental specialist supervise both practitioners and intern.

Nine hundred seventy nine (979) dentists work at Nineveh Health Directory / Ministry of Health / Iraq as recorded in the final statistical analysis in 2019 / December. We exclude 24 dentist recorded as postgraduate students, as well recording the total numbers of each group (DI., DP., DS.) are proofed as present in the governorate (Figure 1).

With exclusion of twenty four dentists from total 979 dentist work in healthcare centers in Nineveh as they are postgraduate students usually in preparation of thesis they will. Rests of dentists are distributed according to qualifications and gender as shown in Figure 1. It's obvious that female dental practitioners predilection slightly higher than male $(53.82 \%)$.

Practitioners form the high percent $(603 / 63.14 \%)$, this can be attributed to multiple factors out of the scope of this article. Two hundred forty dentist consented to participate are included in this article divided into three groups each group form of (80) participant.

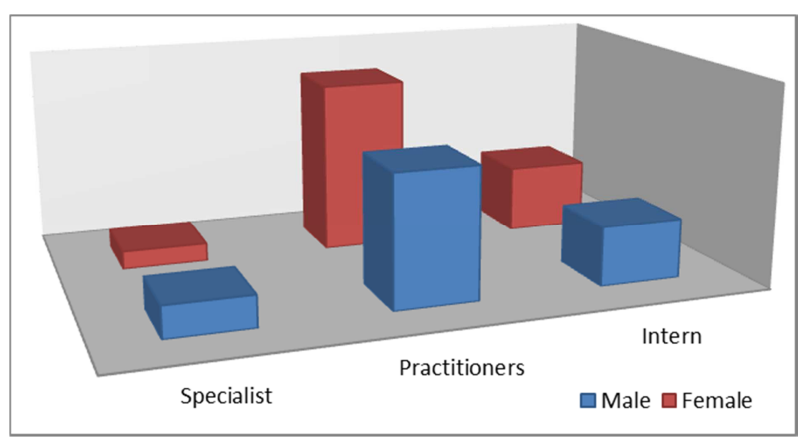

Figure 1. Distribution of Dentists According to Job Title and Gender in Nineveh.

\subsection{Criteria for Participant Selection as Follow}

Inclusion criteria:

Graduated from College of Dentistry, Mosul University

Dentists work in WHO / Iraq

Practicing work not less than six months.

Agree to participate

Exclusion criteria:

Dentist not graduated from College of Dentistry, Mosul University.

Dental practitioners who were absent or not available on the day of the visit.

Dentists who were not willing to participate.

Dentist work in the college of dentistry and students. 
Privet Colleges.

Post graduate students.

Questioners with missing data.

\subsection{Questionnaires}

For data collection we use a revised specialized questionnaires published by Satish Deo and his colleagues in 2018 [4]. A self-administered, 40 - itemed questioner encompassing four sections: general information, knowledge, attitude, and practice of ethics in dental healthcare were employed. Informations assembled through personal contact and social networking via online forms and interview. Proforma questions are deal with the various ethical issues in healthcare management; one of most important question is about "Ethics Guide for Health Service Providers" Book which considered as approved document for the Ministry of Health in Iraq. All ethics lectures which are held in the centers are follow this book.

Questionnaires are validated by the scientific committee in Nineveh health directory. We compare four headlines these are: Demographical data include question of knowing the previously mentioned book, knowledge, Awareness towards healthcare ethics and Practice proper dental ethics among different levels of dentists.

First questionnaire proforma was about general information such that age, sex, and level of education, years of services in the $\mathrm{MOH}$, opinion about ethics and in addition the most important question is about the Ethics Guide for Health Service Providers Book.

The second and third questioner proforma includes different question reflect knowledge and awareness of dentists about dental ethics which should followed in dealing with patients, knowing what's ethical rather than legal. Informed consent, confidentiality of patients is included in the questionnaires list 2 and 3 . The respondents are asked as well about have interest in learning dental ethics and their opinion about drug companies' inducements

Fourth list is evaluating and emphasize dentists executive character in following dental ethics whether in public or private work centers. The respondents reply with yes or no when answering question on ethical issues every day practice.

Each participant will have grades on correct answers, in score of ten marks for the $2^{\text {nd }}, 3^{\text {rd }}$ and $4^{\text {th }}$ questioner list. For the $1^{\text {st }}$ list we focus on answer the question of knowing the book by yes or no.

Microsoft Excel used to record data which analyzed by Statistical Package for Social Sciences (SPSS) software program IBM version 20. A Kruskal-Wallis H test is used to detect the significant difference for each questioner list among groups. In addition Dunn's pairwise comparison also done through using the Bonferrroni test for difference in $\mathrm{p}$ value among groups.

\section{Result}

Age distributions of sample are explained in Figure 2. Most dentists' age are ranged between two levels (less than $28 \mathrm{y}$ and from 36 to $43 \mathrm{y}$ ) with mean age (36.66 years). Figure 3 describe gender frequency in the sample among groups in spite of female forming the high percentage (63.8) in practitioners group but no sex predilection in the total result.

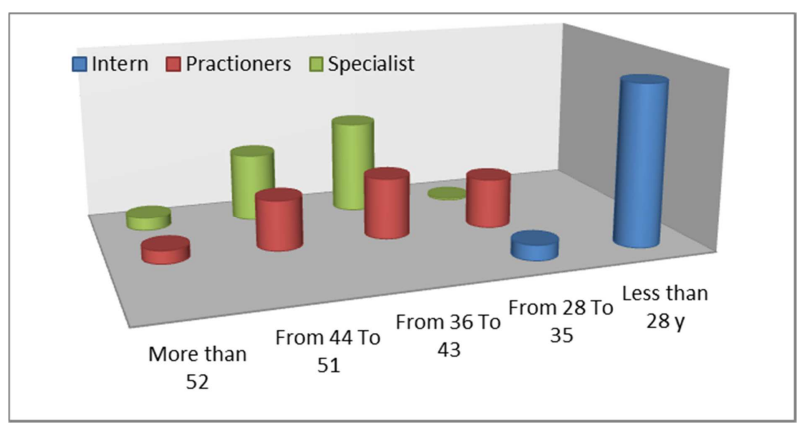

Figure 2. Age distribution among Groups in the Sample.

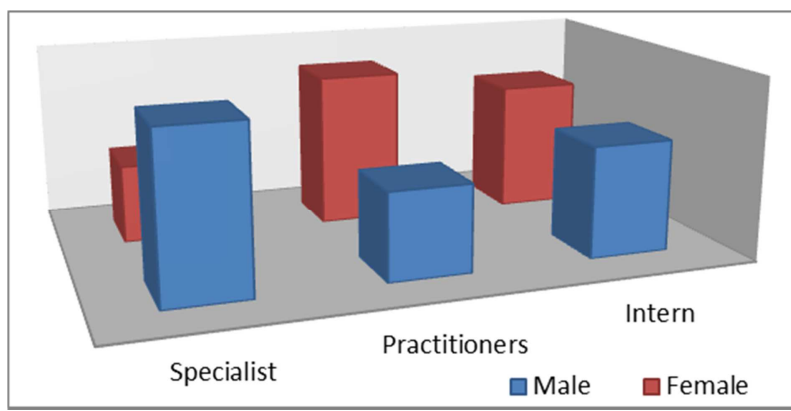

Figure 3. Gender distribution among Groups in the Sample.

Four questionnaires proforma used, inside each list evaluations take place through specific answers criteria in score of ten. SPSS software program used for analysis

As we mention earlier each group is 80 participant answers 4 questioners proforma in score of 10 . Ranks of questioners answering in each proforma for each group are calculated; specialist show a high mean ranks of answers grades (628.09) with slight difference between interne and practitioners in total ranks. Table 1 describe the mean ranks of each group in different proforma.

Table 1. Proforma Mean Ranks for Answers Scores among Groups in the Sample.

\begin{tabular}{lllll}
\hline \multirow{2}{*}{ Groups } & Mean Ranks & & & \\
\cline { 2 - 5 } & Ethics & Knowledge & Awareness & Practice \\
\hline Interne Doctors. & 98.50 & 90.10 & 80.20 & 93.08 \\
Practitioners Doctors. & 115.00 & 104.31 & 118.20 & 361.88 \\
Specialist Doctors. & 148.00 & 167.09 & 163.10 & 45.52 \\
\hline
\end{tabular}

Starting with proforma one (Table 2). It includes the general informations, the hidden question which evaluates their acquaintance about the approved medical ethics book of the Iraqi $\mathrm{MOH}$. The question answered by either yes or no. 
generally speaking 119 (49.58\%) dentist answer by yes. The rest of applicants $121(50.41)$ answer were no. More than $60 \%$ of dental interne doctors don't know the book on the contrary most of specialist know the book. Dental practitioner's answers are to some extent equal.

Table 2. Ethics Quid Answer of Proforma 1.

\begin{tabular}{llll}
\hline Groups & N & Answer & Frequency \% \\
\hline \multirow{2}{*}{ Intern Dr. } & \multirow{2}{*}{80} & Yes & 31.25 \\
& & No & 68.75 \\
Practitioner Dr. & \multirow{2}{*}{80} & Yes & 45 \\
& & No & 55 \\
Specialist Dr. & \multirow{2}{*}{80} & Yes & 72.5 \\
& & No & 27.5 \\
Total & \multirow{2}{*}{240} & Yes & 49.58 \\
& & No & 50.41 \\
\hline
\end{tabular}

Second, $3^{\text {rd }}$ and $4^{\text {th }}$ questionnaire list (Table 3), concentrate on dental ethics knowledge, awareness and practice of dentist's different groups. With score of ten of the answers we consider the grade 4 is the meaning of deficient criteria (InAdequate) and grade 5 and more is the pass grade of knowledge, awareness and practice (Adequate) between the groups. Table 3 explains that in details. More than two-third of participants preserves the knowledge about dental ethics (77.91\%). Third questionnaire list concentrate on dental ethics awareness of dentists; two hundred two dentists are aware of dental ethics importance (84.16\%).

Proforma fourth practicing dental ethics in the public or private work described in table three too, last column it's shown the $90 \%$ of participant practice the ethics guidelines in their institutions. Near half of internes are present with inadequate knowledge but more than two thirds are aware and practice dental ethics respectively $(72.5 \%, 86.25 \%)$.

Table 3. Scores Differences Frequencies according to questioners in the Sample.

\begin{tabular}{|c|c|c|c|c|c|}
\hline Groups & $\mathbf{N}$ & Scores & Knowledge \% & Awareness\% & Practice\% \\
\hline \multirow{2}{*}{ Intern Doctors. } & \multirow{2}{*}{80} & In Adequate & 45 & 27.5 & 13.75 \\
\hline & & Adequate & 55 & 72.5 & 86.25 \\
\hline Practitioner Doctors. & 80 & Adequate & 80 & 80 & 91.15 \\
\hline \multirow{2}{*}{ Specialist Doctors. } & \multirow{2}{*}{80} & In Adequate & 1.25 & ------ & 3.75 \\
\hline & & Adequate & 9875 & 100 & 96.25 \\
\hline Total & 240 & Adequate & 77.91 & 84.16 & 91.24 \\
\hline
\end{tabular}

For analyzing significancy of difference ( $p$ value) among groups in all questioners proforma; statistical analysis performed by use SPSS software. A KruskalWallis $\mathrm{H}$ test provided very strong evidence of a difference $(\mathrm{p}<0.001)$ between the mean ranks of groups. Table 4; show Kruskal Wallis Test Statistic (Grouping Variable group) according to each proforma. High significant differences among groups in the sample are declared (.000).

Table 4. Proforma Kruskal Wallis Test Statistic ${ }^{a, b}$.

\begin{tabular}{llll}
\hline Proforma & Kruskal Wallis & Df & Asymp. Sig \\
\hline Ethics Proforma 1 & 28.118 & 2 & .000 \\
Knowledge Proforma 2 & 56.719 & 2 & .000 \\
Awareness Proforma 3 & 58.607 & 2 & .000 \\
Practice Proforma 4 & 27.962 & 2 & .000 \\
\hline
\end{tabular}

Kruskal Wallis Test

\section{Grouping Variable group}

For illustration of specific group statistical significancy; Pairwise Comparison of Groups in Each Proforma done through use as follows:

Sample 1 and 2 (Interns and practitioners)

Sample 1 and 2 (practitioners and specialist)

Sample 1 and 2 (interns and specialist).

Dunn's pairwise test shows there was very strong evidence ( $\mathrm{p}<0.001$, adjusted using the Bonferrroni correction) of a difference between the specialist and both intern and practitioner (Table 5). No significant difference in 2 sample Pairwise Comparison between dental intern doctors and dental practitioners in both ethics guide and knowledge proforma (P value are $0.83, .191$ respectively). For the rest of comparison $\mathrm{p}$ value were highly significant among samples. Figures 4, 5, 6, 7 show the significant difference of comparisons in Ethics, Knowledge, and Awareness and Practice proforma respectively.

Table 5. Pairwise Comparison of Groups in Each Proforma.

\begin{tabular}{|c|c|c|c|c|c|c|c|c|}
\hline \multirow{2}{*}{ Sample 1- Sample 2} & \multicolumn{2}{|c|}{ Ethics } & \multicolumn{2}{|c|}{ Knowledge } & \multicolumn{2}{|c|}{ Awareness } & \multicolumn{2}{|c|}{ Practice } \\
\hline & Sig. & Adj. Sig. & Sig. & Adj. Sig. & Sig. & Adj. Sig. & Sig. & Adj. Sig. \\
\hline Intern - Practitioner & 0.83 & .248 & .191 & .574 & .000 & .001 & .018 & .054 \\
\hline Intern - Specialist & 0.00 & .000 & .000 & .000 & .000 & .000 & .000 & .000 \\
\hline Practitioner - Specialist & 0.01 & .002 & .000 & .000 & .000 & .000 & .004 & .011 \\
\hline
\end{tabular}

Each row tests the null hypothesis that the sample 1 and sample 2 distributions are the same Asymptomatic significance (2-sided test) are displayed. The significance level is .05 Significance value have been adjusted by
Bonferroni correction for multiple tests. 


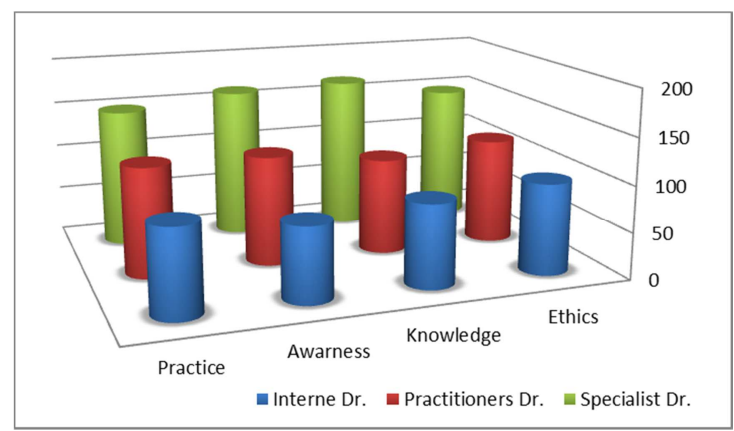

Figure 4. Ranks Differences according to questioners in the Sample.

\section{Pairwise Comparisons of Group}

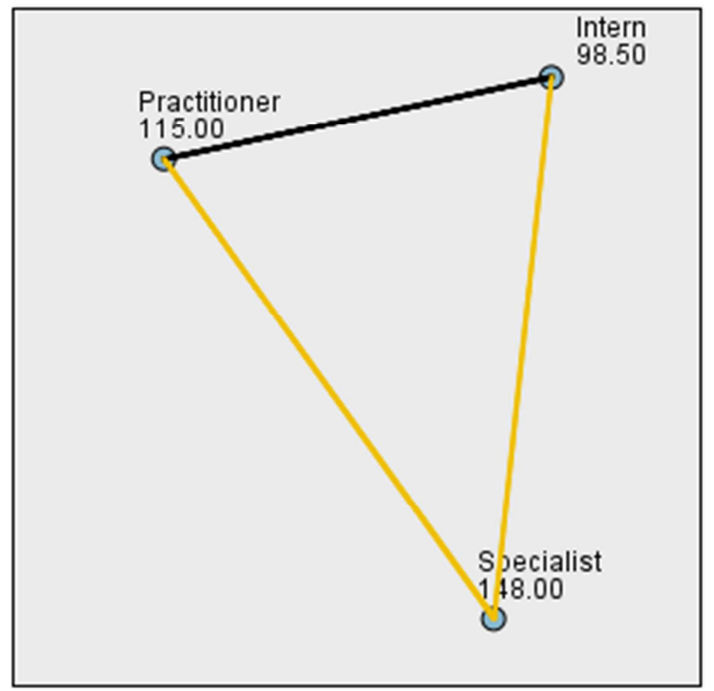

Figure 5. Statistical Significant difference of samples in Ethics Proforma 1.

\section{Pairwise Comparisons of Group}

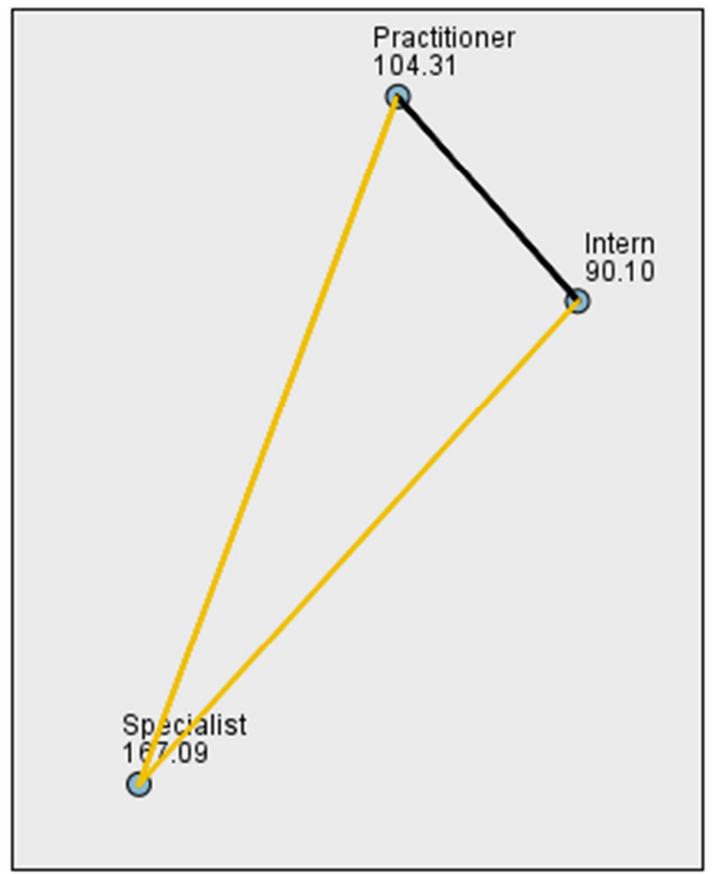

Figure 6. Statistical Significant difference of samples Knowledge Proforma

\section{Pairwise Comparisons of Group}

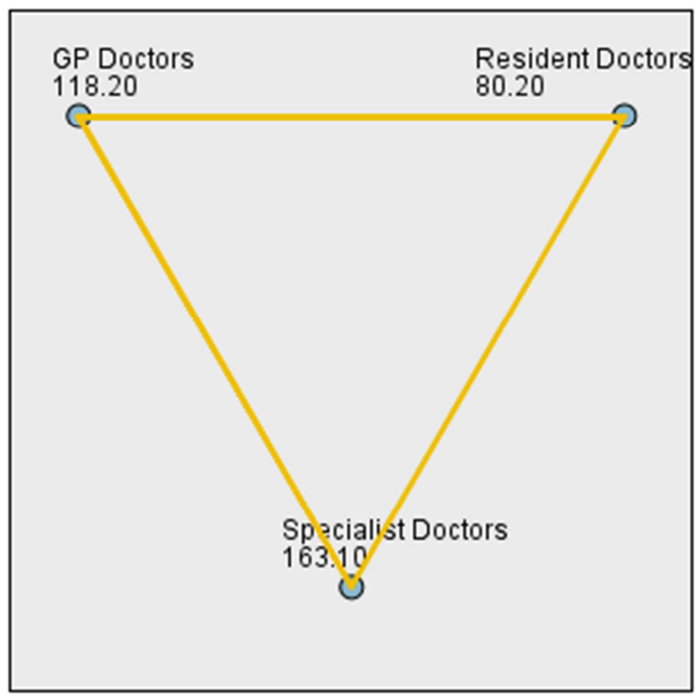

Figure 7. Statistical Significant difference of samples Awareness Proforma 3.

\section{Pairwise Comparisons of Group}

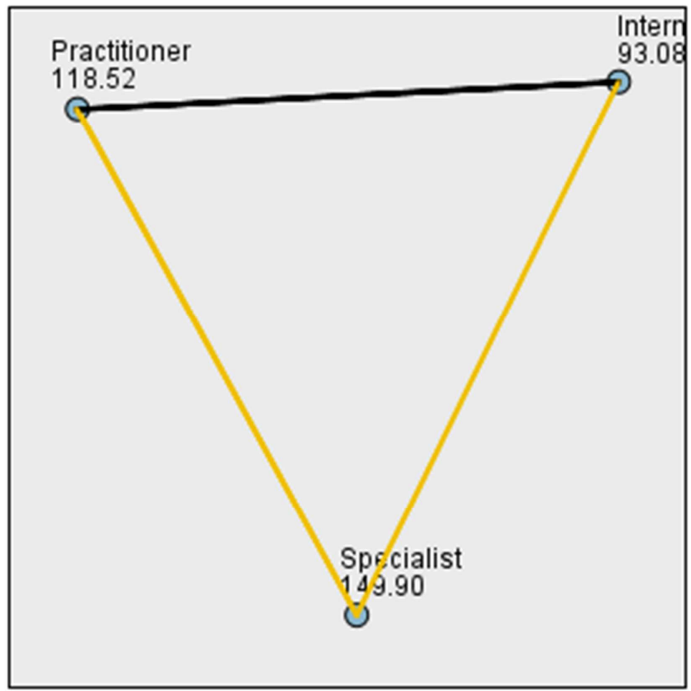

Figure 8. Statistical Significant difference of samples Practice Proforma 4.

\section{Discussion}

Ethics is an innate component reflects personality. Moral principles in ethics attempt to determine what is honestly right and wrong in human action. In the last years professional ethics have gained priority and focus, due to increased public knowledge and development in science and technology $[7,9]$.

Satish Deo etal in his published article in 2018 [4], he supposed that ethics has been ignored in dentistry for long and although it is included in dental curriculum, its significance is not perceived in true spirit. The American dental association defines dental ethics under five fundamental principles that focuses on patients' autonomy, non-maleficence, beneficence, justice and veracity [10]. During healthcare treatment and management, the 
professional, institutional and societal values must be respected and followed.

Oral health dilemmas as well as the understanding level of patients towards dentistry are improved. In most of the world's dental care professionals are starting as dental intern weather in health care centers or hospitals. Every effort must be made to create dentist with a high level of knowledge about dental ethics code and business professionalism similarly need to be well-equipped to deal with variety of ethical issues that arise in due treatment course.

Dental health professionals need to deal with cases involving issues such as patient autonomy, informed consent, competence, rights of conscience, resource allocation, confidentiality, and surrogate decision making [11]. The lack of adequate awareness regarding ethics in practice might be due to lack of application of ethics curriculum in practice.

Sabarinath B etal in his published article 2011 [3] emphasized that the reputation of being a dentist comes with a responsibility to society and to fellow affiliates of profession to carry out one's professional activities in a highly ethical manner [12]. Maintaining highest ethical value obligate the dental professionals to be constantly update their informations about apparent changes that have been noticed regarding what is morally or ethically acceptable to the society in the recent past [13].

My country as other developing nations [14, 15], dental ethics seems to be still in its initial stages related to many situations affect the country with the peoples too. Nineveh considered the third important governorate in my country after the capital Baghdad with more than 2.5 million person live in it. The city Passed with many political difficult situations affect the life in all levels social, economic also scientific drawback.

As far as we search this is probably the first study to assess the knowledge, practices and attitudes related to healthcare ethics among different levels of dentist in my governorate.

Since there is limited information about the knowledge and awareness of dentist consequently we try in this study to highlight this goal.

Questioner collecting data is a simple method which is quick and inexpensive also it's a simple way to reflect the corresponding informations.

In my governorate about 1000 dentist work under the services of $\mathrm{MOH}$ with different level of profession and educations distributed all over the sectors. We chose dentist work in the dental health care centers as they are the mirrors of the specific interface of dentist. Most of training courses and lectures are held there. Similarly these centers are responsible for training the dental intern for [1-2 years]. Dental trainers are observed by practitioner and specialist in different units.

Lectures focus on professional dental ethics are given by specialist have been chosen by ethical committee in Nineveh Health Directory. Great efforts are given by these specialists try to make dental ethics well known and practiced truthfully weather in publicly or privately. Ethical courses and lectures usually not take attention from the audience as much as scientific courses do.

From the concept of that medical service quality and patient safety might affect by the ethics knowledge gaps at the same time emphasize the ideas of dentist about dental ethics we achieve the main purpose of this article. Through four questionnaires proforma, evaluation of general information about dental ethics, knowledge, attitude, and practice of the dentist are done.

Although of difficulties in life, dentists are keen to follow moral principles in patient's relation at work. Significant differences between groups are recorded.

Specialists dentist illustrate high score in all questionnaires lists with significant difference $[P$ value 0.000$]$ that can be attributed to multi reasons as example postgraduate periods were usually learns about importance of ethics in preparing the manuscripts, moreover a possible explanation might be that specialist are expected to be good idol for others relating to their educational status and experience additionally better work experience, dental practice as well exposure to dental ethics during their specialization. The opportunity to share best practices and experiences with foreign dentist and attain continuing medical education from other countries can be added reason for the high knowledge and awareness of specialists [16].

Although of that the three groups are practicing ethics in their work but practitioners as well the intern show few knowledge about the ethics guide approved by the Iraq Ministry of Health [55\%, 68.75\% respectively]. Dental practitioners are usually loaded with multiple jobs in the centers make them practicing ethics more than knowing ethics theoretically although they attained scientific meetings, lectures and courses held inside or outside the country. The interns give the lowest knowledge which can be attributed to that usually intern have no magnetism to reach the ethics courses although of diminished informations they have. They like to be in clinical work, practicing job as they are supported and observed by the practitioners in training centers, seeking to build professional personality more [17].

Study done by Kemparaj VM [18] explains that there was a concern among panelist that there is a lack of knowledge and attitude of health-care ethics among our dental professionals. The authors stated that empirical studies have shown that the physicians, dentists, and nurses have valued the knowledge of ethics importance, but the majority of studies have shown poor knowledge of ethics and health law which has resulted in a violation of ethical principles [19-23]. Contrastingly, some of the studies have reported well to fair knowledge among dental professionals [22, 24, 25].

Age incidences of the participant between $25-60$ years with mean age [36.66 years], years of services spend in the profession definitely give experts in the field ethical, clinical and practice. In this article we don't correlate the knowledge to the years of services statistically but from the style of answering the questionnaires we can observe that increasing knowledge seen with increasing years of services $[1,4,5]$.

Gender comparison demonstrates participation of more female as general practitioners as they are already much 
more than males as expressed by the statistical analysis of dentist [Figure 1]. Female as general practitioners are forming the high incidences which is logic as female are already show more incidence in the survey [342 female practitioners], we think that marital situation and family obstacles can reduce the desire of post-graduation probably. No sex predilection in the total result $[5,26]$.

Generally speaking the results of this article are really encouraging as $77.91 \%$ have knowledge, $84.16 \%$ act and behave according to dental ethics, and 91.26 practicing ethics in total groups. On the contrary of study done Sabarinath B. 1128 dental clinics in Chennai concludes that dental practitioners not follow ethics appropriately in their clinical practice [3].

The evolution of science and technology with advances in medicine require great attention for patients as they are the important part in this field. All shares to know about the right of each, together with the frustration of a poorly cleared procedure. For that reason ethical processes established, which highlights the need for greater communication between professionals and patients.

\section{Limitations of This Study}

In this study we encountered limitations as we don't focus on ethics code in details such that consent form. As well we need to highlight satisfaction of dentist about role of ethics committee in public and private work. Beside that we should encouraging intern and practitioners to attain these lectures with scheduled examinations and evaluations should organize. We need to high light knowledge about consumer protection to gain high quality dental care.

\section{Conclusion}

Reputation to be part of medical healthcare persons make dentist forced to follow the ethical roles in the country where he live and should be an ideal example for others in the society as we are the mirrors of each other's. More efforts should spend to teach intern the importance of dental ethics as priorities similar to scientific clinical work.

\section{Suggestion}

Dental ethics syllabus is better to be emphasized, continuous courses and lectures with written documents should take place in more spread way.

We should pay attention to importance of patients as a human being first and as patient second.

Medico- legal courses should be also provided to be legally on safer side.

\section{Acknowledgements}

Grate appreciation and thanks to the Scientific Committee in Nineveh Health Directorate.

\section{References}

[1] Anup N, Himanshu K, Gautam B, Sonia P, Swasti T. Knowledge, attitude \& practices regarding ethics \& law amongst medical and dental professionals in Rajasthan - a questionnaire study. Iosr Jdms. 2014; 13 (5): 102-109. doi: 10.9790/0853-1354102109.

[2] Nazish I, Imran I, Masood J, Nauman M. Health ethics education: knowledge, attitudes and practice of healthcare ethics among interns and residents in Pakistan. JPMI. 2014; 28 (4): 383-389.

[3] Sabarinath B, Sivapathasundharam B. Ethics in dentistry. J Educ Ethics Dent. 2011; 1: 24-27.

[4] Satish Deo, Sujaya Gupta, Anjana Maharjan, Shumneva Shrestha. Health care Ethics among Dental Intern Doctors. JNDA | Vol. 17 No. 2 Jul-Dec 2017. https: //www.researchgate.net/publication/328631200.

[5] Executive Committee. Ethiopian Medical Association. Medical Ethics for Doctors in Ethiopia. Addis Ababa, Ethiopia: Produced and publicized by: Ethiopians Medical Association (EMA); April, 2016.

[6] Nash DA. Ethics, Empathy, and Education of Dentists. J of Dent Educ. 2010; 74 (6): 567-78.

[7] Williams, John R. Dental Ethics Manual (FDI) (C) 2007 by FDI World Dental Federation. 1942. ISBN 0-9539261-5-X. www.fdiworldental.org.

[8] Abdul-Salam S Sultan. Ministry of Health / Iraq. Principles of medical ethics in Iraqi health institutions December / 2017. https: //www.researchgate.net/publication/321995363.

[9] Ozar DT, Sokol D J. Dental Ethics at Chair side: Professional Principles and Practical Applications. Washington, DC: Georgetown University Press, 2002. 2nd ed. pp272. ISBN 0878403760 .

[10] Al-Zain SA, Al-Sadhan SA, Ahmedani MS. Perception of BDS students and fresh graduates about significance of professional ethics in dentistry. J Pak Med Assoc. 2014; 64 (2): 118-23).

[11] Aulisio MP, Arnold RM, Youngner SJ. Health care ethics consultation: nature, goals, and competencies. A position paper from the Society for Health and Human Values-Society for Bioethics Consultation Task Force on Standards for Bioethics Consultation. Ann Int Med. 2000; 133 (1): 59-69.

[12] CDA Code of Ethics. Adopted by the California Dental Association Journal. 2006; 34: 60-62.

[13] Prasad K, Hegde C, Jain A, Shetty M. Philosophy and principles of ethics: Its applications in dental practice. J Educ Ethics Dent. 2011; 1: 2-6.

[14] Kazemian A, Berg I, Christina F, Yazdani S, Hans-F Z, Philipp Jl. How much dentists are ethically concerned about overtreatment; a vignette-based survey in Switzerland. BMC Medical Ethics (2015) 16: 43.

[15] Chambers DW. Finding our place in dental ethics. Pa Dent J. 2009; 76 (3): 27-31.

[16] Mesafint A Tiruneh, Birhanu T Ayele, Kidanemariam GM Beyene. Knowledge of, and attitudes toward, codes of ethics and associated factors among medical doctors in Addis Ababa, Ethiopia Medicolegal and Bioethics. Dovepress submit your 2019: 9 1-10. 
[17] Schochow M, Christel A, Lautenschläger C, Steger F. Dentists' Knowledge of Ethical Questions Regarding Dental Medicine A Survey of Dentists from Saxony, Saxony-Anhalt and Thuringia (Germany). Gesundheitswesen 2016; 78 (12): e168e173 DOI: $10.1055 / \mathrm{s}-0035-1548930$.

[18] Kemparaj VM, Panchmal GS, Kadalur UG. The Top 10 Ethical Challenges in Dental Practice in Indian Scenario: Dentist Perspective. Contemporary Clinical Dentistry, 01 Jan 2018, 9 (1): 97-104. DOI: 10.4103/ccd.ccd_802_17 PMID: 29599593 PMCID: PMC5863419.

[19] Kress GC, Hasegawa TK, Jr, Guo IY. A survey of ethical dilemmas and practical problems encountered by practicing dentists. J Am Dent Assoc. 1995; 126: 1554-62. [Abstract] [Google Scholar].

[20] DuVal G, Sartorius L, Clarridge B, Gensler G, Danis M. What triggers requests for ethics consultations? J Med Ethics. 2001; 27 (Suppl 1): i24-9. [Europe PMC free article] [Abstract] [Google Scholar].

[21] Breslin JM, MacRae SK, Bell J, Singer PA. University of Toronto Joint Centre for Bioethics Clinical Ethics Group. Top 10 health care ethics challenges facing the public: Views of Toronto bioethicists. BMC Med Ethics. 2005; 6: E5. [Europe PMC free article] [Abstract] [Google Scholar].
[22] John JS. A Study on the Awareness among the Doctors about Consumer Protection Act in a Selected Hospital. Dissertation Rajiv Gandhi University of Health Sciences. 2005 [Google Scholar].

[23] Hariharan S, Jonnalagadda $R$, Walrond $E$, Moseley $H$. Knowledge, attitudes and practice of healthcare ethics and law among doctors and nurses in Barbados. BMC Med Ethics. 2006; 7: E7. [Europe PMC free article] [Abstract] [Google Scholar].

[24] Milind TW. Awareness of medico-legal issues among medical and dental college health professionals of Vadodara, Gujarat. J Indian Assoc Public Health Dent. 2011; 9: 280-4. [Google Scholar].

[25] Gupta VV, Bhat N, Asawa K, Tak M, Bapat S, Chaturvedi P, et al. Knowledge and attitude toward informed consent among private dental practitioners in Bathinda City, Punjab, India. Osong Public Health Res Perspect. 2015; 6: 73-8. [Europe PMC free article] [Abstract] [Google Scholar].

[26] Kazemian A, Yazdani S. Dentists in the mirror of Dentists :A survey on peer assessment of dental ethics in Iran. SADJ August 2017, Vol 72 no 7 p305-p309. 